\title{
An Airplane Calculator Featuring a High- Fidelity Methodology for Tailplane Sizing
}

\author{
Bento Silva de Mattos ${ }^{1}$, Ney Rafael Secco
}

\begin{abstract}
The present work is concerned with the accurate modeling of transport airplanes. This is of primary importance to reduce aircraft development risks and because multi-disciplinary design and optimization (MDO) frameworks require an accurate airplane modeling to carry out realistic optimization tasks. However, most of them still make use of tail volume coefficients approach for sizing horizontal and vertical tail areas. The tail-volume coefficient method is based on historical aircraft data and it does not consider configuration particularities like wing sweepback angle and tail topology. A methodology based on static stability and controllability criteria was elaborated and integrated into a MATLAB application for airplane design. Immediate advantages with the present methodology are the design of realistic tail surfaces and properly sized airplanes. Its validation was performed against data of five airliners ranging from the regional jet CRJ-100 to the Boeing 747-100 intercontinental airplane. An existing airplane calculator application incorporated the present tail-sizing methodology. In order to validate the updated application, the Fokker 100 airliner was fully conceptually designed using it.
\end{abstract}

KEYWORDS: Aircraft design, Tailplane design, Aircraft stability and control.

\section{INTRODUCTION}

It is of fundamental importance for any optimization framework tailored to airplane design the use of realistic airplane models. If the disciplines that are embedded in the airplane modeling are not accurate enough, it makes no sense performing any optimization tasks, because the resulting planes may be unviable to develop or deliver an acceptable performance. Thus, the present work is concerned with the development of a computational tool able to properly model transport airplane configurations. An existing computational tool that was christened Aeronautical Airplane (AA) was enhanced with an improved approach for tailplane sizing (Mattos and Magalhães, 2012).

Tail surfaces are used to both stabilize the aircraft and provide control authority that is needed for maneuver and trim. For a conventional aircraft configuration, the tail often has two components, the horizontal and the vertical tails. The primary functions of these components are: take care of airplane trim and stability, and provide control by the elevator and rudder surfaces which are associated with the horizontal and vertical tails, respectively.

With regard to aircraft stability, the purpose of horizontal tail (HT) is to maintain the longitudinal stability; while the vertical ones is responsible for keeping the directional stability. Here, we refer to two stability concepts: static and dynamic. Aircraft static stability is defined as the tendency of an aircraft to return to the original trimmed conditions if diverted by a disturbance. Major disturbance sources are gusts and pilot inputs on the controls. On the other hand, the dynamic longitudinal one is related to the motion of a statically stable airplane, the way that it will return

三 1.Instituto Tecnológico de Aeronáutica - São José dos Campos/SP - Brazil

三 Author for correspondence: Bento Silva de Mattos | Instituto Tecnológico de Aeronáutica | Praça Marechal Eduardo Gomes, 50 - Vila das Acácias | CEP: $12.228-900$ São José dos Campos/SP - Brazil | Email: bmattos@ita.br

Received: 04/06/13 | Accepted: 10/10/13 
to equilibrium after suffering some kind of disturbance. Basically, there are two primary forms of longitudinal movements with regard to an airplane attempting to return to equilibrium after being disturbed. The first one is the phugoid mode of oscillation, which is a long-period and slow oscillation of the airplane's flight path; the second is a short-period variation of the angle of attack. Usually, this oscillation decreases very quickly with no pilot input (Centennial of Flight, 2011). However, the Centennial of Flight website introduces some misconceptions about Dutch roll, when it states that: "Dutch roll is a motion exhibiting characteristics of both directional divergence and spiral divergence." Therefore, Dutch-roll basic cause is the unbalance between lateral and longitudinal stabilities, when the latter is considerably lower than the first one.

The tail surfaces of transport airplanes are usually designed to obey static stability criteria. If some undesirable dynamic behaviors become evident during a flight test campaign, fixes are provided to overcome the problems. Typical fixes are dorsal and ventral fins, vortex generators, strakes, and in some extreme cases, stablets. The results obtained with an in-house application for tailplane sizing corroborate this statement, as will be shown in the next sections of this work.

As to the controllability topic, it can be stated that an airplane is fully controlled when a flight condition may be changed in a finite time by appropriate control inputs at any new flight condition. In general, a system is considered controllable if it can be transferred from selected initial conditions into chosen final states. The controllability thus describes the influence of external inputs (in general, the controlled variables) to the inner system state. About this, an important distinction must be made between output and state controllability. Output controllability is the notion associated with the system output; the output controllability describes the ability of an external input to move the output from any initial condition to any final one in a finite time interval. No relationship must exist between state and output controllability. The state of a system, which is a collection of its variables values, completely shows the system at any given time. Particularly, no information on the past of a system will help to predict the future, if the states at the present time are known. Complete state controllability (or simply controllability if no other context is given) describes the ability of an external input to move the internal state of a system from any initial one to any other final in a finite time interval.

Concerning transonic airplanes, tail surfaces should be composed of low-thickness and/or higher sweep than that adopted for the wing, in order to prevent strong shocks on the tail in normal cruise. As required for certification regulations and safety purposes, transport airplane must dive in an emergency event occurring at high altitudes. The main reason behind this is to reach another one, where no onboard oxygen is needed for the passengers to breath. In this situation, for high-speed airplanes, the airflow over the wing becomes fully detached and the airplane counts just on the horizontal tailplane to depart from the dive. This provides a good reason for airflow remaining attached to HT at this high-speed condition. Former airplane design teams used to increase the HT quarter-chord sweepback angle relative to that figure of the wing (typically a 5 degrees plus). Although providing higher sweepback angles to HT will mean a longer arm relative to center of gravity (CG) and a higher lift curve slope, modern multidisciplinary design and optimization (MDO) frameworks are able to find out the optimal planform and airfoil shapes for tailplanes. Thus, modern design airplanes not necessarily follow the +5 degrees rule to set such angle for the horizontal tail.

In order to keep weight and drag as low as possible, typical values for the maximum relative thickness for both HT and vertical tail (VT) lie in the range of 8 to $11 \%$. Besides working with lower hinging moments, airfoil shapes for the HT shall present a very low maximum camber in order to avoid the generation of undesired induced drag and to maintain interference drag with the tailcone or the VT as low as possible. It is worth mentioning that the tailcone is a region of high decelerating airflow, and the thickness of boundary layer increases fast and dramatically. Thus, interference drag is a big issue when integrating conventional HTs into the airframe.

Typical aspect ratios for HT vary from four to five. T-tails present sometimes higher aspect ratios (5-5.5) to avoid aftengine/pylon wake effects (Sadraey, 2009). Usual aspect ratios for VT range from 1.2 to 1.8 with lower values for T-tails. Taper ratios of about 0.4 to 0.6 are typical for tail surfaces, since lower ones would lead to unacceptably small Reynolds numbers (Sadraey, 2009). T-tail vertical surface taper ratios are in the range of 0.85 to 1.0 to provide adequate chord for attachment of the HT and associated control linkages (Sadraey, 2009). 
A large variety of tail shapes has been employed on aircraft since the beginning of powered aviation in the early $20^{\text {th }}$ century. These include configurations often denoted by the letters whose shapes they resemble in front view: $T, V, H,+, Y$, inverted $V$. The selection of the particular configuration includes complex system-level considerations.

Most of existing MDO frameworks for aircraft design makes use of tail volume coefficient or scaling factors approach for tailplane calculation. A relatively new example of this can be seen in the paper by Grundlach (1999). The tail volume coefficient approach is based on statistical data and may lead to tailplanes that are unable to comply with stability and controllability requirements. In the present work, a more sophisticated and higher fidelity methodology for the design of tail surfaces was compiled from the specialized literature, then coded using MATLAB platform, validated by comparing calculated tail areas to those from some current airliners, and incorporated into an airplane calculator software. Static stability and controllability criteria were used for the design of HTs and VTs of airplanes under consideration.

\section{METHODOLOGY}

\section{AIRPLANE CALCULATOR TOOL}

$\mathrm{AA}$ is a MATLAB application that calculates transport airplane characteristics, performance, and layout. User must provide to it information regarding geometry, configuration, topology, wing and tailplanes airfoils, range at given payload, passenger capacity, and engine data of the configuration that is due to be analyzed.

AA makes use of a wing-body full potential code with boundary-layer correction for wings employing the strip sense approach (Karas and Kovalev, 2011). This code is known as BLWF and it is able to automatically generate a multi-block mesh from user-provided configuration parameters. The approximate-factorization algorithm AF2 is used for marching in pseudo time (Holst and Thomas, 1982). Aerodynamics coefficients are calculated using Roskam Class II methodology (Roskam, 2000a) and Torenbeek's formulation to estimate divergence Mach number of wings and HTs (Torenbeek, 1982).
Loads calculations are performed with BLWF for some points in the airplane operational envelope (Fig. 1). Afterwards, the calculated loads are used to estimate the wing structural weight applying Megson's method in some sections of the wingbox (Fig. 2). Elastic deformation is well iteratively, since the loads will vary when the wing deforms (Fig. 3). The procedure that was adopted for the wing-box sizing is described in Videiro (2012).

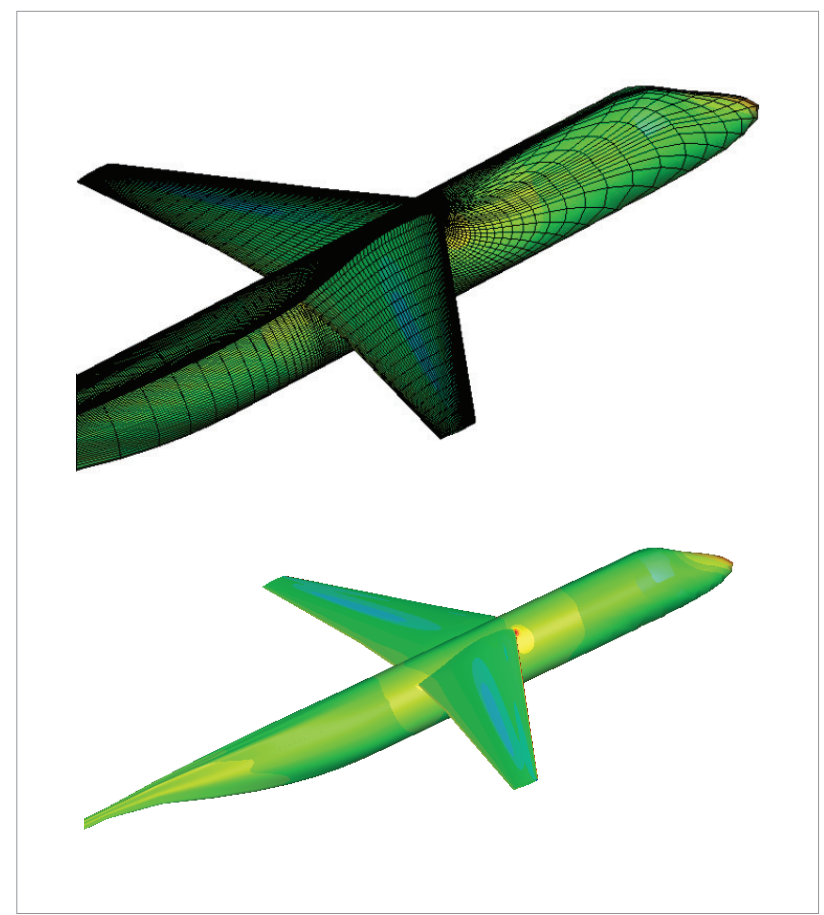

Figure 1. A full-potential code that accounts for viscous effects is used by Aeronautical Airplane. It is able to handle both low- and high-wing configurations.

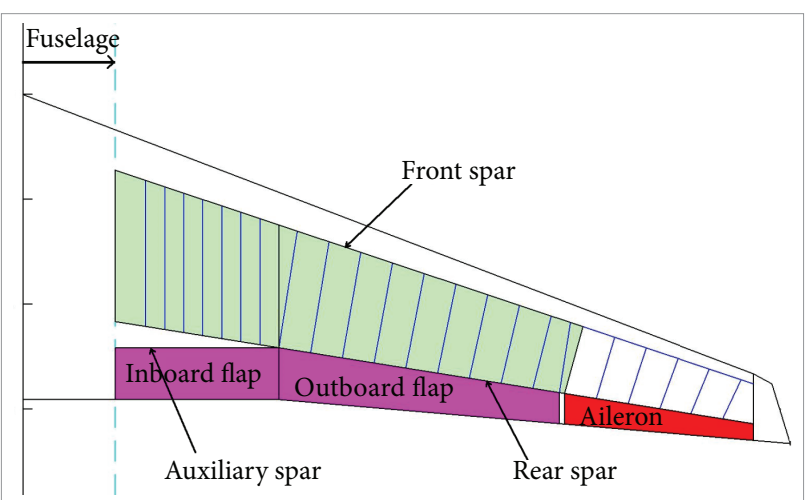

Figure 2. Spars and ribs belong to the wing layout defined by Aeronautical Airplane for a configuration with engines positioned at aft fuselage. The green area shown above indicates availability for fuel storage. 


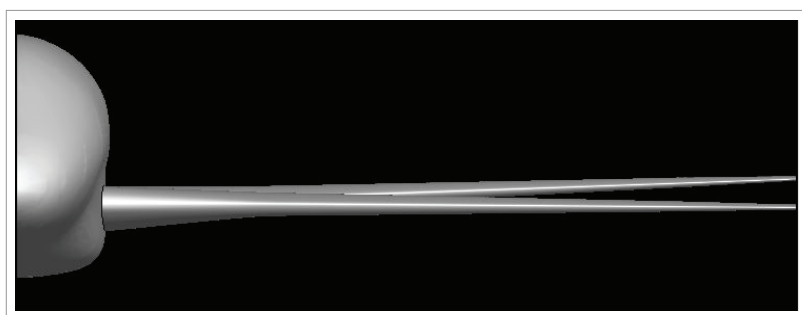

Figure 3. Example of wing elastic bending deformation calculated by Aeronautical Airplane.

BLWF is also used in conjunction with XFOIL for the estimation of the $C_{\text {Lmax }}$ for the configuration under study. It is used to calculate the maximum lift coefficient of some sections along the wingspan and BLWF estimates the $C_{\text {Lmax }}$ of the configuration using those values in the technique of the critical section.

The turbofan engine model employed by AA is described in Loureiro (2008), who developed a generic deck for turbofan engines based on Benson's work (Benson, 1995). Fan diameter, bypass ratio, fan pressure ratio, engine parts efficiencies, design point, turbine inlet temperature, and overall pressure ratio are some input variables to this model. Typical outputs from the engine module are fuel flow and thrust.

AA also defines the fuselage cross section (Fig. 4) and the design diagram, the latter clustering several Federal Aviation Rules (FAR - from the United States), 25 performance conditions together, enabling a better comprehension of thrust and wing loading figures to fulfill requirements (Fig. 5). Scholz (2011) provided several guidelines that were used to define the fuselage cross section as seen in Fig. 4. The methodology that was employed to generate graphs like the one displayed in Fig. 5 is described in Roskam (2000).

AA calculates fuselage geometry, CG envelope, engine thrust and consumption chart, operational envelope, direct operating cost (DOC), payload-range diagram, airplane flight mechanics, takeoff path, maximum takeoff weight (MTOW) with all airplane component weights, engine emissions, and noise signature.

It must be emphasized that AA does not enforce the airplane under study to obey the requirements in Fig. 4, considering that it is indeed a transport airplane analysis tool, not a design one. If the intent is to design an airplane, AA can be without great effort easily incorporated into a design and optimization framework, considering that modern airplane conceptual design must make use of optimization tools.

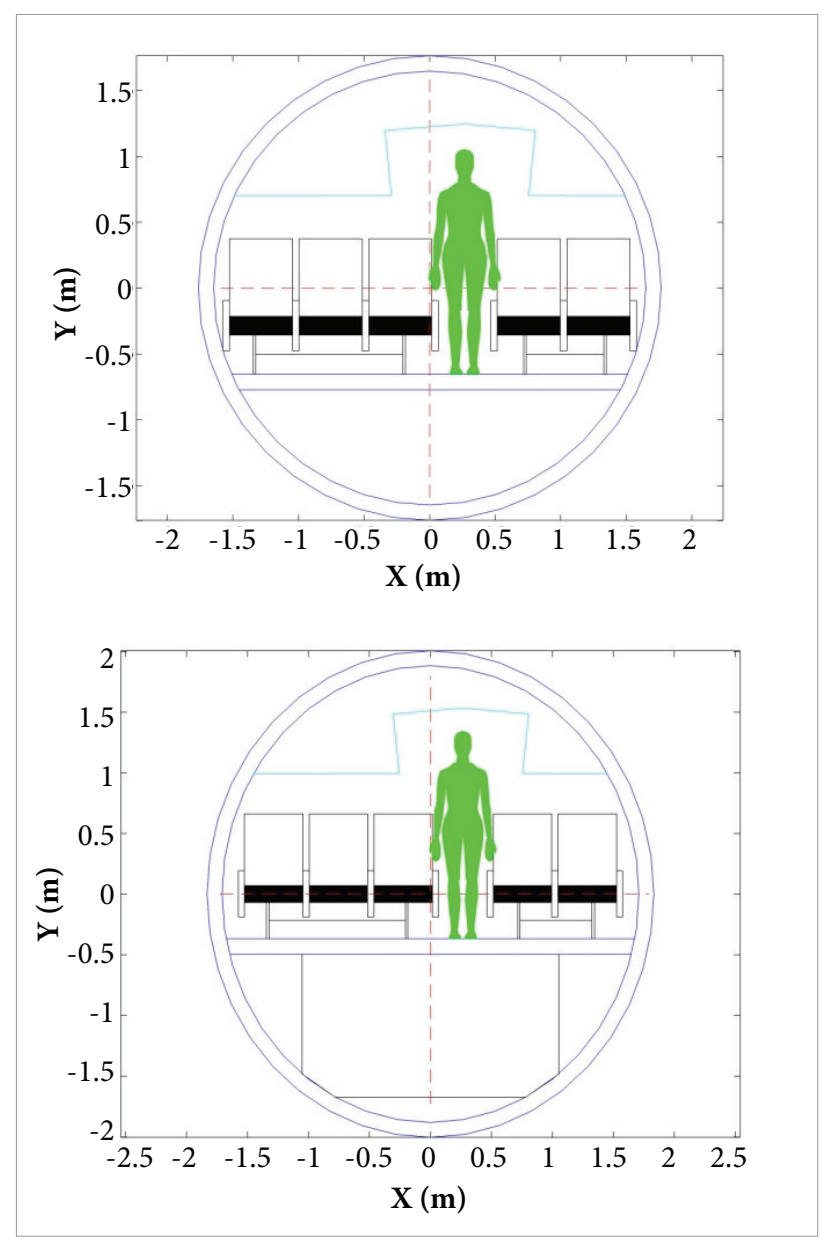

Figure 4. Aeronautical Airplane output of some fuselage cross sections.

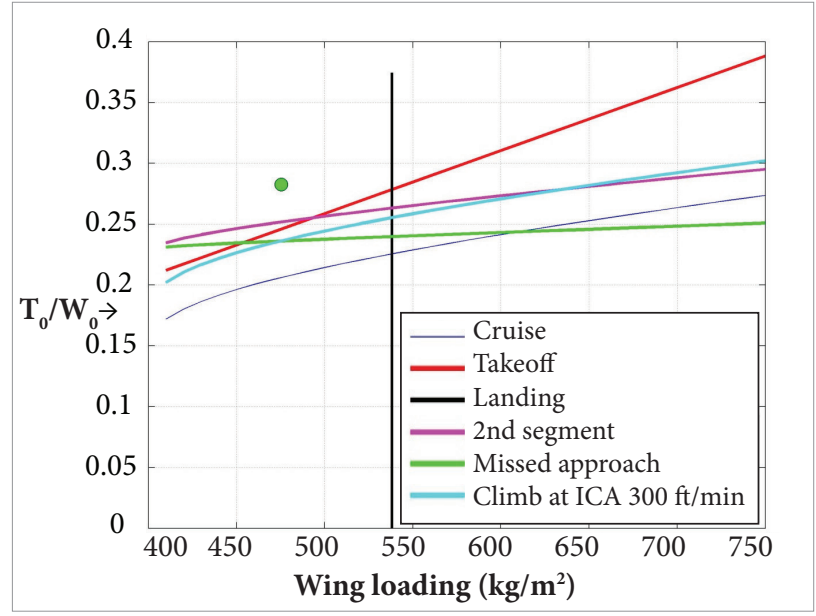

Figure 5. Design diagram of the airplane configuration being investigated (green circle). Criteria like the second segment climb and rate of climb at initial cruise altitude (ICA) are employed to verify whether the configuration comply or not with FAR design requirements (Roskam, 2000). 


\section{ENHANCED TAIL SIZING METHOD}

Takeoff is a critical condition for tailplanes design, and therefore some relevant aspects of this flight phase are described in the following paragraphs. Figure 6 illustrates the takeoff segments for airplanes. $V_{1}$ is the takeoff decision speed, $V_{R}$ the rotation speed, $V_{\text {Lof }}$ velocity of liftoff, and $V_{2}$ is the flight speed over a hypothetical 35 -feet obstacle. During the initial phase of the takeoff path, the airplane must be accelerated on the ground to $V_{E F}$, at which point the critical engine must be made inoperative and remain like this for the rest of the takeoff. $V_{1}$ means the maximum speed in the takeoff at which the pilot must take the first action, such as: apply brakes, reduce thrust, deploy speed brakes, and stop the airplane within the accelerate-stop distance. It also means the minimum speed in the takeoff, following a failure of the critical engine at $V_{E F}$, at which the pilot can continue it and achieve the required height above the takeoff surface within its distance (Boeing, 2009).

According to FAR 25.149, $V_{\text {mca }}$ is the calibrated airspeed at which:

- critical engine suddenly becomes inoperative;

- control of the airplane is possible to maintain;

- maintain straight flight;

- bank angle shall be lower than five degrees;

- $V_{\text {mca }}$ may not exceed $1.2 \times V_{s}$.

The conditions for determination of $V_{\text {mca }}$ are:

- maximum takeoff thrust on remaining engines;

- most unfavorable CG (usually aft CG), where the tail moment arm is the shortest);

- aircraft trimmed for takeoff (takeoff flap setting);

- maximum TOGW;

- most critical takeoff configurations along the flight path, except for landing gear retracted.

$V_{\text {mca }}$ is used for determining the minimum $V_{R}$ and $V_{2}$. The $V_{2}$ must also be chosen in order to satisfy the second segment climb requirement. $V_{\text {mca }}$ must be lower than the $V_{2}$ and considering its importance for aircraft performance and safety operation, it was calculated after the tail surfaces had been obtained. For this purpose, the methodology elaborated by Cavanaugh (2004) was incorporated in the present work.
The main objective of the present paper was the calculation of the HT and VT areas through a higher fidelity method than that offered by the tail volume approach. In order to accomplish this, static stability and controllability criteria were employed for the design of the horizontal and vertical tails. The VT area is obtained by taking the larger one from that calculated employing both criteria, while the HT area is obtained with the procedure described previously. Stability derivatives that are needed for the calculation of HT and VT areas were obtained according to Roskam's methodology (Roskam, 1971). Initial estimated values are required in order to start iterative processes for the HT and VT calculation. MATLAB's fsolve minimization algorithm was employed for the calculation of the tailplanes areas. Indeed, no optimization of the tail-plane areas was carried out with fsolve. This MATLAB tool is used to find out the tailplane areas, because they depend on several parameters and variables such as wing location along the fuselage.

The incorporation of a more sophisticated methodology for the tail-plane sizing into AA poses a more complex task in the interactive process for MTOW calculation. The determination of the CG location is needed not only for the tail-plane area measurement, but also to position the main and nose landing gear, which is also dependent on the overall CG location, which will guide the wing placement in the configuration. The modified AA was employed to calculate the characteristics of an airplane similar to Fokker 100, a 107-seater airliner. By varying the quarter-chord wing sweepback angle, the impact on HT and $\mathrm{VT}$ areas was obtained.

\section{BASELINE AIRPLANE}

Fokker 100 is a medium size twin-turbofan airliner design and market by the extinct Dutch company, Fokker. It is a complete redesign of the Fokker F-38, which rivals the BAE 146. It had longer wings, and fuselage that would seat over 100 passengers and a "glass" cockpit featuring six large displays (World's Aircraft, 2013). In 1988, Fokker flew an uprated Rolls\&Royce Tay 650 powered version, which American Airlines ordered 75 aircraft with 75 options. The baseline airplane that was chosen in the present work was Fokker 100 fitted with Rolls\&Royce Tay 620 engines. Table 1 presents some relevant data for such airplane. 


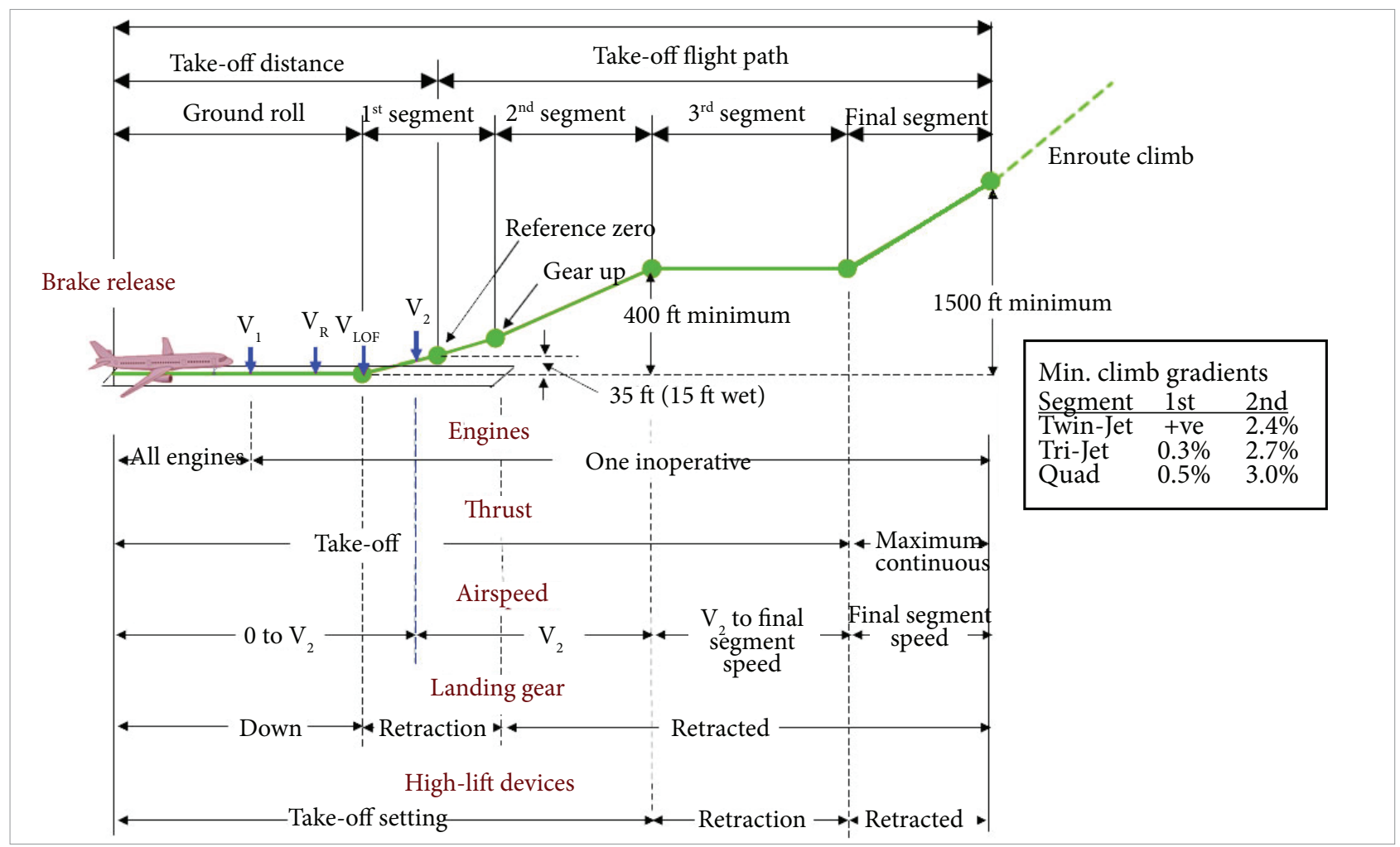

Figure 6. Illustration of take-off segments and required FAR climb requirements.

Table 1. Data for the Fokker 100 fitted with Tay 620 engines.

\begin{tabular}{|l|c|}
\hline \multicolumn{2}{|c|}{ Performance } \\
\hline Maximum operating Mach number & 0.77 \\
\hline Service ceiling & $35,000 \mathrm{ft}$ \\
\hline Maximum range with maximum payload & $1,720 \mathrm{~km}$ \\
\hline Maximum takeoff weight & $43,090 \mathrm{~kg}$ \\
\hline \multicolumn{1}{|c|}{ Wing } \\
\hline Aspect ratio
\end{tabular}

\section{HORIZONTAL STABILIZER}

\section{Design for controllability}

The aircraft trim must be guarantee three axes, $x, y$, and $z$, namely the lateral, longitudinal, and directional ones, respectively. When the summation of all forces in $x$ direction (such as drag and thrust) is zero and of all moments including aerodynamic pitching moment about $y$ axis is zero, the airplane is longitudinally trimmed.

HT can be installed at airplane tail-cone or on top of vertical tails. Some airplanes like the Piaggio Avanti business turboprop are fitted with foreplanes that are located at forward fuselage. Such foreplanes are known as canards.

The HT is responsible for maintaining longitudinal trim and making the forces summations to be zero, by generating a necessary lift and contributing in the summation of moments in $y$ axis. When the summation of all forces in $y$ direction (such as side force) is zero; and of all moments including aerodynamic yawing moment about $z$ axis is zero, the aircraft is said to have the directional trim.

In order to trim longitudinally, we obtained the airplane seen in Fig. 7. 


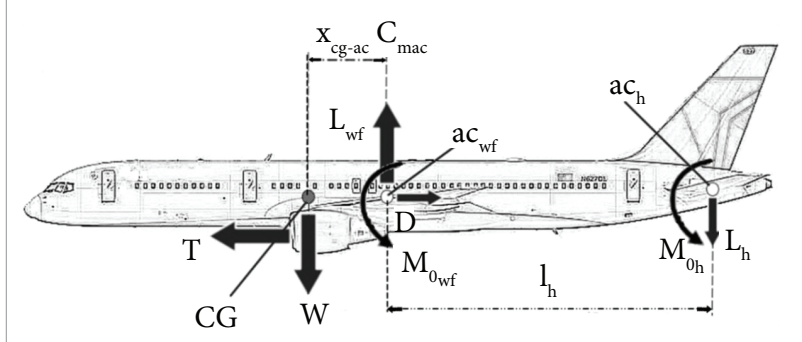

Figure 7. Forces and moments acting for longitudinal trim.

$$
M_{0_{w f}}+M_{0_{h}}+M_{0_{e}}+L_{w f} x_{c g-a c} c_{m a c}-L_{h}\left(l_{h}+x_{c g-a c} c_{m a c}\right)=0
$$

where $x_{c g-a c}$ is the ratio between the distance of aerodynamic center of the wing to CG and the mean aerodynamic chord of the wing (static margin).

Equation 1 can be further developed and we can obtain Eq. 2:

$$
\begin{aligned}
& \frac{\rho V^{2}}{2} S_{w} c_{m a c}\left[C m_{0_{w f}}+C m_{0_{e}}+C_{L_{w f}} x_{c g-a c}\right]= \\
& \eta_{h} \frac{\rho V^{2}}{2} S_{h}\left[C_{L_{h}} l_{h}-c_{m a c} C m_{0_{h}}+C_{L_{h}} c_{\text {mac }} x_{c g-a c}\right]
\end{aligned}
$$

Finally, an expression for the area ratio is derived (Eq. 3):

$\frac{S_{h}}{S_{w}}=\frac{\left[C m_{0_{w f}}+C m_{0_{e}}+C_{L w f} x_{c g-a c}\right] c_{m a c}}{\eta_{h}\left[C_{L h}\left(l_{h}+x_{c g-a c} c_{m a c}\right)-c_{m a c} C m_{0_{h}}\right]}$

Another form of Eq. 4 is as follows:

$$
\frac{\eta_{h} S_{h} l_{h}^{\prime} C_{L_{h}}}{S_{w} c_{m a c}}=C m_{0_{w f}}+C m_{0_{e}}+C_{L_{w f}} x_{c g-a c}
$$

with Eq. 5:

$l_{h}^{\prime}=l_{h}+x_{c g-a c} c_{m a c}$

and $\mathrm{Cm}_{0 \mathrm{~h}} \sim 0$, considering that horizontal stabilizers are composed of airfoil sections, which present maximum camber approximately equal to zero.

The combination $S_{h} l_{h}^{\prime} / S_{w} c_{\text {mac }}$ in Eq. 4 is an important nondimensional parameter for the HT design, and is referred to as the "HT volume coefficient" (Eq. 6). The name is originated from the fact that both numerator and denominator have the unit of volume (e.g. $\mathrm{m}^{3}$ ). The numerator is a function of HT parameters, while the denominator is of wing parameters (Eq. 6):

$V_{h}=\frac{S_{h} l_{h}^{\prime}}{S_{w} c_{\text {mac }}}$

Table 2 shows typical $V_{h}$ figures for some aircraft types. The tail volume coefficient is an indication of handling quality in longitudinal stability and control. As the $V_{h}$ increases, the aircraft tends to be more longitudinally stable, and less longitudinally controllable. The fighter aircraft that is highly maneuverable tend to have a very low tail volume coefficient. Transport airplanes require a higher one because they are tailored to perform in a stable flight, for passenger and crew's comfort.

The $V_{h}$ parameter is a crucial variable in HT design and is selected at the early stages of aircraft conceptual phase.

\begin{tabular}{|c|c|c|c|c|c|c|}
\hline Airplane & Type & MTOW [kg] & Wing area $\left(\mathrm{m}^{2}\right)$ & Overall length $(\mathrm{m})$ & HT area $\left(m^{2}\right)$ & $\mathbf{V}_{\mathrm{h}}$ \\
\hline Cessna 172 & $\begin{array}{c}\text { Light GA } \\
\text { (piston powered) }\end{array}$ & 1,100 & 16.2 & 7.9 & 1.94 & 0.76 \\
\hline Piper PA-46-350P & $\begin{array}{l}\text { Light transport (piston } \\
\text { powered) }\end{array}$ & 1,950 & 16.26 & 8.72 & - & 0.66 \\
\hline Alenia G222 & $\begin{array}{l}\text { Military transport } \\
\text { (turboprop) }\end{array}$ & 28,000 & 82 & 22.7 & - & 0.85 \\
\hline Fokker 100 & $\begin{array}{c}\text { Jet airliner } \\
\text { (R\&R Tay 620) }\end{array}$ & 43,090 & 93.5 & 32.5 & 21.72 & 1.07 \\
\hline Boeing F/A-18C & Fighter & 23,400 & 46 & 16.8 & - & 0.49 \\
\hline Pilatus PC-12 & $\begin{array}{c}\text { Multipurpose } \\
\text { single-engine turboprop }\end{array}$ & 4,100 & 25.81 & 14.14 & - & 1.08 \\
\hline Airbus A340-200 & Jet airliner & 257,000 & 363.1 & 59.39 & 72.90 & 1.11 \\
\hline Boeing 747-400 & Jet airliner & 396,830 & 525 & 68.63 & 136.60 & 0.81 \\
\hline
\end{tabular}
Although one of the primary functions of the HT is to provide longitudinal stability, the tail volume coefficient

Table 2. Tail volume coefficients for some airplanes (Sadraey, 2009). 
serves as a significant parameter both in the longitudinal stability and longitudinal trim issues (Sadraey, 2009). On the other hand, this parameter is usually chosen by looking at similar aircraft. In fact, in the aircraft design, each parameter depends on everything else of the configuration in a non-linear and very complex fashion. In modern conceptual design, MDO frameworks have a commonplace in the aircraft industry (Mattos and Magalhães, 2012). Therefore, the horizontal tail, as well as the vertical stabilizer, shall be designed concurrently with wing and fuselage for a clean and efficient design, and picking up a tail volume coefficient makes no sense anymore.

\section{Design for stability}

Another design requirement must be examined: aircraft static and dynamic longitudinal stability. The static longitudinal stability is examined through the sign of the longitudinal stability derivative $C_{m a}$ or the location of the aircraft neutral point; the dynamic behavior is associated with autonomous motions such as Dutch roll, spiral divergence and other issues linked to flight quality, which will not be considered in the present work.

For an aircraft with a fixed aft tail, the aircraft longitudinal stability derivative is determined as Eq. 7:

$C m_{\alpha}=\frac{d C_{m}}{d \alpha}=d\left\{\frac{C m_{0_{w f}}+L_{w f} \times\left(x_{a c}-x_{c g}\right)+C m_{0_{h}}-L_{h} \times\left[l_{h}+\left(x_{a c}-x_{c g}\right)\right]}{1 / 2 \rho V^{2} S_{w} c_{\text {mac }}}\right\} / d \alpha(7)$

Taking into account that, we have Eq. 8:

$$
\begin{aligned}
& L_{h}=C_{L 0_{h}}+C_{L \beta_{h}} \eta_{h} S_{h}\left(1-\frac{d \varepsilon}{d \alpha}\right), \\
& C_{m \alpha}=\left(C_{L \alpha_{w f}}+C_{L \alpha_{h}} \eta_{h} \frac{S_{h}}{S_{w}}\left(1-\frac{d \varepsilon}{d \alpha}\right)\right) x_{a c-c g}-C_{L \alpha_{h}} \eta_{h} \frac{S_{h}}{S_{w}} \frac{l_{h}}{c_{m a c}}\left(1-\frac{d \varepsilon}{d \alpha}\right)
\end{aligned}
$$

Because the tail operates in the downwash field of the wing (for conventional, aft-tail configurations), the effective tail angle of attack is reduced. According to Roskam (1971), the parameter $d \varepsilon / d \alpha$ can be estimated by Eq. 9:

$$
\frac{d \varepsilon}{d \alpha}=4.44\left[k_{A} k_{\lambda} k_{h} \sqrt{\cos \Psi_{w 25}}\right]^{1.19} \frac{\left(C_{L \alpha_{w}}\right)_{M}}{\left(C_{L \alpha_{w}}\right)_{M=0}}
$$

where:

$$
\begin{aligned}
& k_{A}=\frac{1}{A R_{w}}-\frac{1}{1+A R_{w}^{1.7}} \\
& k_{\lambda}=\frac{10-3 \lambda_{w}}{7} \\
& k_{h}=\frac{1-\left|z_{h} / b\right|}{\sqrt[3]{2 l_{h} / b}}
\end{aligned}
$$

The relationship $\left(C_{L \alpha_{w}}\right)_{M} /\left(C_{L \alpha_{w}}\right)_{M=0}$ can be calculated by using the following expression (Eq. 11):

$C_{L \alpha_{w}}=\frac{2 \cdot \pi \cdot A R_{w}}{2+\sqrt{A R_{w}^{2} \cdot\left(1+\tan ^{2} \Psi_{50}-M_{\infty}^{2}\right)+4}}$

When the derivative $C_{m a}$ is negative or the neutral point is behind the aircraft CG, the aircraft is said to be statically longitudinally stable. The limit of the design is found when Eq. 9 is set to zero and therefore Eq. 12 is obtained.

$$
\frac{S_{h}}{S_{w}}=\frac{C_{L \alpha_{w f}} x_{c g-a c}}{\left\{C_{L \alpha_{h}} \eta_{h}\left(1-\frac{d \varepsilon}{d \alpha}\right)\left[x_{c g-a c}+\frac{l_{h}}{c_{m a c}}\right]\right\}}
$$

\section{Obtaining the horizontal tail area}

Eqs. 4 and 12 provide two relationships between the area ratio $\left(S_{h} / S_{w}\right)$ and $x_{c g-a c}$. These equations can now be combined into a single graph (Scholz, 2011). It should be observed that the aft center of gravity must be positioned at a safe distance to the natural stability limit. For a jet transport aircraft, Roskam established this value as 5\% of MAC. However, according to Raymer (1999), this can be further reduced to $3 \%$ of MAC. The permitted areas of focus are now between the limit lines of controllability and those of the stability requirement. Between these lines now, the required CG range can thus be fitted to find out the smallest HT surface area. The region of interest lies above the horizontal green line in Fig. 8.

Table 3 shows the CG variation for some airliners. The three-engine DC-10 intercontinental airliner has the lowest CG variation among all airplanes listed in Table 2. Figures for the 737-800 and Boeing 777-200 were obtained from Boeing's training material (Boeing, 2009) and the remaining ones from Chai and Mason (1996). 


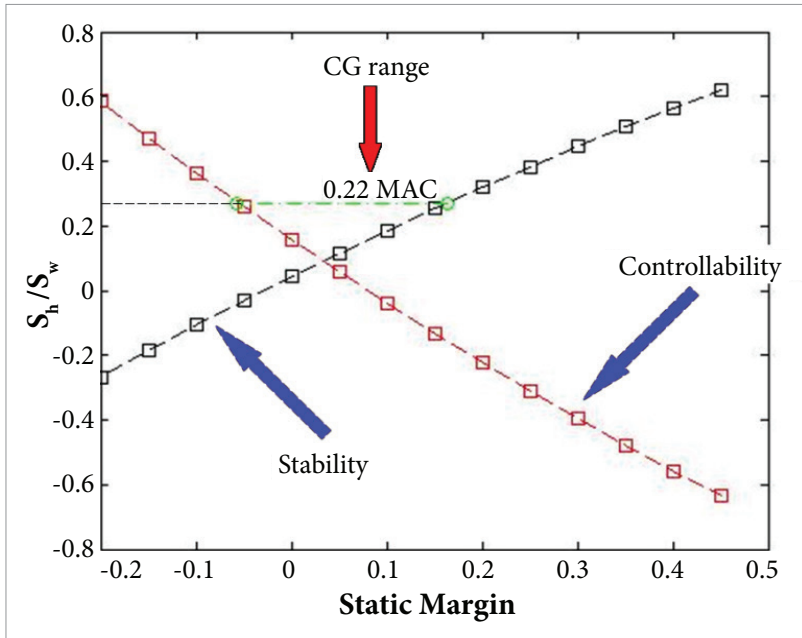

Figure 8. Illustration of the calculation procedure for horizontal tail area ratio. Static margin is the variable $x_{\text {cg-ac }}$.

Table 3. CG variation for some airliners (Chai and Mason, 1996, Boeing, 2011).

\begin{tabular}{|l|c|c|}
\hline \multicolumn{1}{|c|}{ Airplane } & $\begin{array}{c}\text { Fore/aft } \\
\text { [\% MAC] }\end{array}$ & $\begin{array}{c}\text { Variation } \\
\text { [\% MAC) }\end{array}$ \\
\hline Boeing 737-800 & $5 / 36$ & 31 \\
\hline Boeing 767 & $11 / 32$ & 21 \\
\hline Boeing 747-400 & $8.5 / 33$ & 24.5 \\
\hline Boeing 777-200 & $14 / 44$ & 30 \\
\hline DC-10 & $8 / 18$ & 10 \\
\hline
\end{tabular}

\section{VERTICAL STABILIZER}

Two criteria were adopted for the vertical stabilizer sizing: static stability and controllability. The first condition is related to stability. The tailplane may be sized to fulfill a desired coefficient value that incorporates the variation of yawing moment coefficient with yaw angle, $C_{n \beta}$. The fuselage and VT are the airplane components that significantly impact its directional stability. When an airplane experiences a sideslip angle, in general the fuselage alone will generate a moment that tends to increase the sideslip angle, which is a destabilizing and undesirable condition. The VT plays a major role to the static directional stability. When the airplane experiences a sideslip angle, the VT has the same aerodynamic effects as wings at angle of attack, but at different planes. Thus, it generates a moment relative to airplane's CG, which produces a stabilizing one that tends to neutralize the sideslip angle. The VT usually has a low aspect ratio, which provides a higher stall angle than high-aspect ratio planforms. If stall occurs, a catastrophic situation may result due to the steady increase of the sideslip angle. Ventral fins and stablets are good options to improve Dutch-roll characteristics without an unacceptable weight penalty. These surfaces provide a stable yawing moment at larger sideslip angles. The second consideration for vertical tailplane sizing is associated with controllability. This criterion may be determinant for a multi-engined underwing configuration. Loss of power on the number 1 engine, which are numbered from port to starboard, requires that the pilot simultaneously apply right rudder to correct the resulting yaw moment due to asymmetric thrust condition. Also, it should be applied a rolling moment to the right both to hold the starboard wing low and balance the rolling moment due to the rudder. The low starboard wing produces a side force on the airplane that balances that generated by the rudder deflection.

Engine failure at takeoff poses a critical condition for the VT design. In this case, the remaining engine (or engines) must provide enough thrust to maintain the required rate of climb with the additional drag caused by rudder and aileron deflections. Trim drag due to rudder deflection and to a lesser extent aileron deflection may be critical in meeting FAR.121 climb requirements for the second segment, especially for twin-engine airplanes.

An additional vertical tail-sizing requirement, which is harder to calculate, is to keep directional control while on the ground. The tail must be sized such that the minimum control speed on the ground $\left(V_{M C G}\right)$ is less than the takeoff decision speed $\left(V_{1}\right)$. If this is not the case, and $V_{M C G}$ is greater than $V_{1}$, then the situation may arise in which critical engine failure occurs above $V_{1}$. In such situation, the pilot has to continue the takeoff (because $V_{1}$ has been exceeded), but the airplane lacks adequate lateral control while still on the ground. The requirements for $V_{M C G}$ are given in FAR 25.149(e). They are to lose the most critical engine, apply the rudder (without the use of nose wheel steering), and maintain control down the runway with a maximum of 30 feet $(\sim 10 \mathrm{~m})$ lateral deviation from the runway centerline. In flight test, this is performed at successively lower speeds until the pilot can no longer maintain 30 feet lateral deviation. If additional control power is required for a derivative design (such as having increased engine thrust), improved rudder effectiveness may be achieved by adding vortex generators to the vertical stabilizer (as was done on the L1011 for one customer with particularly short runway, and reduced $V_{m c a}$, requirements). If that does not work, a doublehinged rudder might fix the problem. This was done on the 
Boeing 747SP (along with increased tail height) to make up for the shortened fuselage (and thus reduced rudder moment arm), and also on the DC-10.

\section{Design for controllability}

The required yawing moment coefficient to maintain steady flight with one failed outboard engine at 1.2 times the stall speed is as specified by FAR 25.149. The remaining outboard engine must be at the maximum available thrust, and the bank angle cannot be larger than five degrees. Figure 9 shows the engine-out situation for a twin-engine configuration. The engine-out constraint is established by constraining the maximum available yawing moment coefficient $\left(C_{n_{\text {available }}}\right)$ to be greater than the required one $\left(C_{n_{\text {req }}}\right)$ for the engine-out flight condition (Eq. 13):

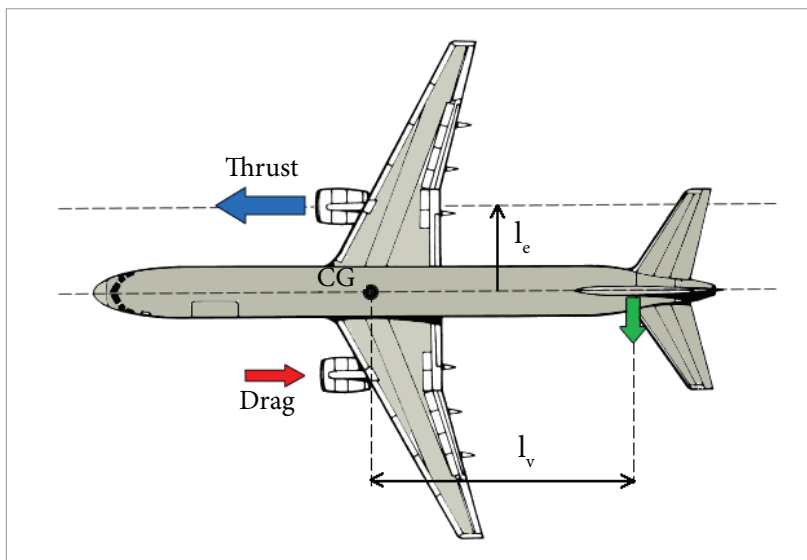

Figure 9. Engine-out situation of a twinjet airplane.

$$
C_{n_{\text {req }}}=\frac{\left(D_{\text {windmill }}+T\right) \cdot l_{e}}{q S_{\text {ref }} b_{w}}
$$

In Eq. 14, $T$ is the takeoff thrust and $D_{\text {windmill }}$ is the wind milling drag of the failed engine.

The drag due to the wind milling of the failed engine is calculated using the method described in Appendix G-8 of Torenbeek (1982). Thus, we have

$$
D_{\text {windmill }}=C_{D_{\text {windmill }}} q S_{\text {ref }}
$$

where

$$
C_{D_{\text {windmill }}}=\frac{0.075 d_{i}^{2}+\frac{2 \pi d_{i}^{2}}{1+0.16 M_{\infty}^{2}} \frac{V_{n}}{V}\left(1-\frac{V_{n}}{V_{n}}\right)}{S_{\operatorname{Re} f}}
$$

In Eq. 15, $V_{n}$ is the nozzle exit velocity and $V_{\mathrm{n}} / V=0.92,0.42$ for high- and low-bypass ratio turbofans, respectively. Torenbeek's wind milling drag equation (Torenbeek, 1982) was validated against the flight test data of 747 (Grasmeyer, 1998). Torenbeek's equation for the estimation of wind milling drag coefficient shows relatively good agreement with the flight test data over a range of Mach numbers.

The maximum available yawing moment coefficient is obtained at an equilibrium flight condition with a given bank angle and a maximum rudder deflection $(\delta r)$. The bank angle is limited to a maximum of five degrees by FAR 25.149, and the aircraft is allowed to have some sideslip $(\beta)$ (Grasmeyer, 1998). The sideslip angle is found by summing the forces along the y-axis:

$C_{y \delta a} \delta_{a}+C_{y \delta r} \delta_{r}+C_{y \beta} \beta+C_{L} \sin \phi=0$

We considered in the present work that $\beta=1$ and $\phi$ is obtained from Eq. 17:

$\phi=\arcsin \left[-\frac{\left(C_{y \beta} \beta+C_{y \delta a} \delta_{a}+C_{y \delta r} \delta_{r}\right)}{C_{L}}\right]$

Considering that $C_{\mathrm{y} \delta \mathrm{a}} \sim 0$, Eq. 17 can be simplified to Eq. 18: $\phi=\arcsin \left[-\frac{\left(C_{y \beta} \beta+C_{y \delta r} \delta_{r}\right)}{C_{L}}\right]$

If $\phi$ calculated by Eq. 18 is greater than $5^{0}$, we set this value for $\phi$ in Eq. 16 and then $\beta$ is obtained instead of fixing a value for $\phi$. Thus, if the pilot slightly increases the sideslip angle further than one degree, he/she will have a safe margin for the increase of the $C_{n_{\text {available }}}$. In addition, if one engine is inoperative, drag could become a critical issue if the sideslip angle were excessively increased.

After the values for $\beta$ and $\phi$ are known, the aileron deflection required to maintain equilibrium flight is obtained by summing the rolling moments about the $x$-axis:

$C_{l \delta a} \delta_{a}+C_{l \delta r} \delta_{r}+C_{l \beta} \beta=0$

$\delta_{a}=\frac{-C_{l \delta r} \delta_{r}-C_{l \beta} \beta}{C_{l \delta a}}$

The rudder deflection is initially set to the given maximum allowable steady state value, and the bank angle and aileron 
deflections for equilibrium flight are determined by Eqs. 19a and $b$. The maximum allowable steady-state deflection is typically 20 to 25 degrees. This allows for an additional fivedegree of deflection for maneuvering.

The maximum available yawing moment is found by summing the contributions due to the ailerons, rudder, and sideslip (Eq. 20):

$$
C_{n_{\text {avail }}}=C_{n \delta a} \delta_{a}+C_{n \delta r} \delta_{r}+C_{n \beta} \beta
$$

\section{Design for stability}

The remained condition for the design of the vertical stabilizer considers that the airplane is experiencing a sideslip angle (Fig. 10). In this situation, the yaw moment balancing when a sideslip angle is present is enforced

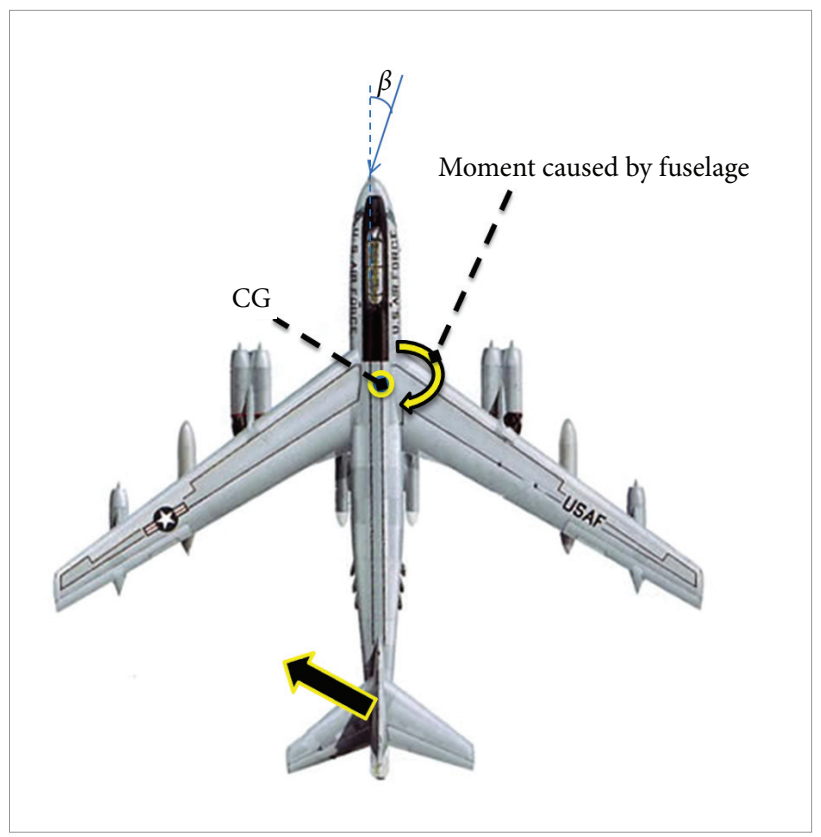

Figure 10. The vertical tail has a stabilizing effect when the airplane is experiencing a sideslip angle.

$M_{\text {Resulting }}=M_{V T}+M_{\text {wing }}+M_{\text {fuselage }}$

Eq. 21 can be further developed resulting in Eqs. 22 and 23.

$$
\begin{aligned}
& \frac{1}{2} \rho V^{2} b_{w} C_{n \beta_{\text {aiplome }}} \beta=\frac{1}{2} \rho V^{2} b_{w} C_{n \beta_{V T}} \beta+\frac{1}{2} \rho V^{2} b_{w} C_{n \beta_{\text {ping }}} \beta+\frac{1}{2} \rho V^{2} b_{w} C_{n \beta_{\text {jisclage }}} \beta \\
& C_{n \beta_{\text {aiplane }}}=C_{n \beta_{V T}}+C_{n \beta_{\text {wing }}}+C_{n \beta_{\text {fiselage }}}
\end{aligned}
$$

Terms in Eq. 23 are calculated according to Roskam's methodology (Roskam, 1971):

$C_{n \beta_{\text {wing }}} \cong 0$

$C_{n \beta_{V T}}=-C_{y \beta_{V T}} \frac{\left(l_{v} \cos \alpha+z_{v} \sin \alpha\right)}{b_{w}}$

The stability derivative $C_{y \beta V T}$ in Eq. 26 can be calculated by

$C_{y \beta V T}=-k_{C y \beta V T} C_{L \alpha V T}\left(1+\frac{d \sigma}{d \beta}\right) \eta_{v} \frac{S_{V T}}{S_{\operatorname{Re} f}}$

where

$$
\begin{aligned}
& k_{C y \beta V T}=0.75 \frac{b_{v}}{d_{f, v}}<2 \\
& k_{C y \beta V T}=\frac{1}{6} \frac{b_{v}}{d_{f, v}}+\frac{5}{12} \quad 2 \leq \frac{b_{v}}{d_{f, v}}<3.5 \\
& k_{C y \beta V T}=1 \frac{b_{v}}{d_{f, v}} \geq 3.5
\end{aligned}
$$

and

$$
\left(1+\frac{d \sigma}{d \alpha}\right) \eta_{v}=0.724+3.06 \frac{S_{v} / S_{w}}{1+\cos \Psi_{1 / 4}}+0.4 \frac{Z_{w}}{d}+0.09 A R_{w}
$$

In Eq. 30, $Z_{w}$ is a vertical distance between the wing quarter-chord at the location of mean aerodynamic chord and the fuselage centerline, positive downwards.

Eq. 24 is analyzed at the beginning and end of the cruise. The most critical condition is then considered.

\section{RESULTS}

Before integrating the present methodology into an airplane design application, a numerical tool written in MATLAB $^{\circledR}$ language was developed for tailplane analysis only. The main reason for creating such tool was the validation of the methodology described in the preceding sections. This tool, which was named ITAIL, presents a graphical interface as shown in Fig. 11. Stability derivatives were calculated according to the methods proposed by Roskam (1971). The incorporation of ITAIL into AA will be further described. 


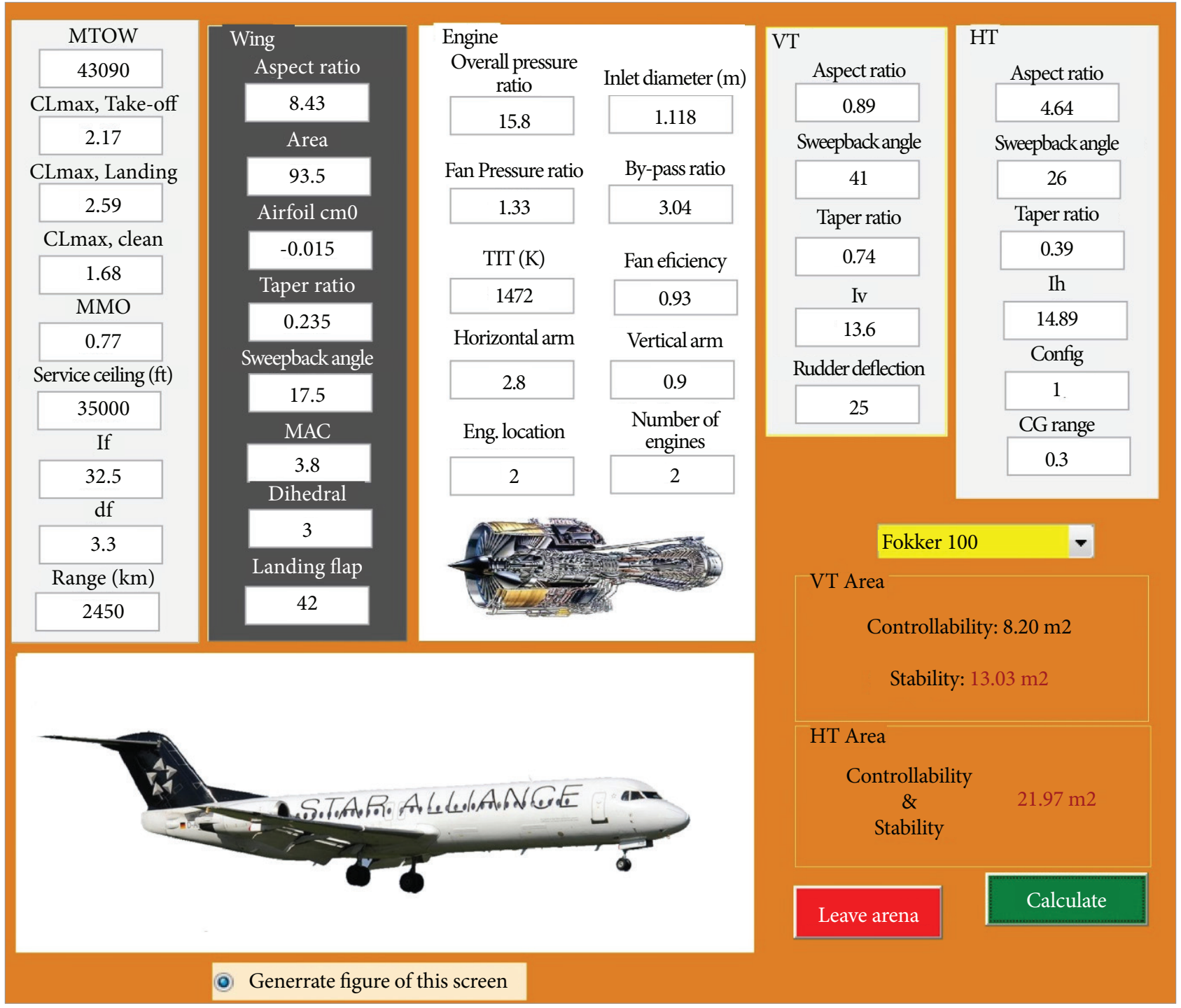

Figure 11. Main panel of ITAIL, a tailplane sizing application written in MATLAB ${ }^{\circledR}$.

\section{ITAIL}

ITAIL offers users the possibility of choosing some airliners from a drop-down menu. A broad range of airliners is represented from the regional jet CRJ-100 to the Boeing 747-100. Some characteristics of the airplanes used in the validation process are listed in Table 4. Both T-tail as well as the conventional tail configuration were considered. Aircraft manufacturers usually bring into market stretched or shortened variants featuring some shared components with a baseline configuration. Usually, stabilizers are designed for the baseline configuration in some cases, taking into account characteristics of the remaining ones. Stretched versions will not be the cause of major concerns because the HT and VT arms will turn these surfaces more effective. However, shortened ones will require larger tailplanes. For this reason, the validation airplanes considered here are baseline configurations from which others were derived. Most airplane data used for ITAIL validation were taken from online sources (Jenkinson, Simpkin and Rhodes, 2011).

Table 5 compares some calculated stability derivatives to values obtained from flight tests (Heffley and Jewell, 1972). Calculated values for the airliners that were taken for validation are shown in Table 6. The highest deviation found was that for the Boeing 737-100 HT area, 6.5\%. The 
Table 4. Some data belonging to the validation airplanes that were inputted into ITAIL.

\begin{tabular}{|c|c|c|c|c|c|c|}
\hline Airplane & $\begin{array}{c}S_{w} \\
\left(m^{2}\right)\end{array}$ & $\begin{array}{l}\text { MTOW } \\
\text { [kg] }\end{array}$ & $I_{h}$ & $I_{v}$ & $\begin{array}{l}\text { Thrust arm } \\
\text { [m] }\end{array}$ & $\begin{array}{l}\text { cg range } \\
\text { [\% MAC] }\end{array}$ \\
\hline Boeing 757-200 & 185.25 & 115680 & 19.35 & 18.97 & 6.9 & 22 \\
\hline Fokker 100 & 93.5 & 43090 & 14.89 & 13.6 & 2.8 & 30 \\
\hline Boeing 747-100 & 511 & 333400 & 30.54 & 28.35 & 21.3 & 24 \\
\hline CRJ-100ER & 48.35 & 24091 & 12.21 & 9.76 & 2.2 & 30 \\
\hline Boeing 737-100 & 102 & 44225 & 11.97 & 11.04 & 5.0 & 30 \\
\hline
\end{tabular}

agreement between calculated and actual figures for the areas can be considered excellent. The factor that determined the Fokker 100 VT area was stability. Considering that this airplane has aft mounted engines, the controllability criterion is not the critical one. A post-design check in order to guarantee that the dynamic stability behavior will be satisfactory is obviously required.

The results presented here corroborates that tailplanes areas of airliners can be usually determined by considering static stability requirements, with undesired dynamic behavior being fixed during flight test campaign if needed. Furthermore, design teams should be aware that aerodynamic phenomena like high interference drag, wake vortex and localized flow separation can turn tailplanes less effective and this issue must be carefully analyzed. Figure 12 displays the $V_{\text {mca }}$ and stall speed variation with takeoff weight for the B-757-200 airliner. The kink in the graph can be credited to the fact that solution for the $V_{m c a}$ calculation is driven by two kinds of constraints: limitation of rudder or aileron deflection. In fact, the lower boundary represents $60.0 \%$ of the MTOW and may not be an operating condition. $V_{m c a}$ may become an important driver for the design of the VT if takeoff field length or climb requirements in second segment are very stringent.
Table 5. Comparison of calculated stability derivatives to experimental data (Boeing 747-100).

\begin{tabular}{|c|c|c|}
\hline Derivative & $\begin{array}{c}\text { Present work } \\
H=12,200 \mathrm{~m} \\
\mathrm{M}=0.90 / \alpha=1.2^{\circ}\end{array}$ & $\begin{array}{c}\text { Heffley (1972) } \\
H=12,200 \mathrm{~m} \\
M=0.90 / \alpha=2.4^{\circ}\end{array}$ \\
\hline$C_{n \beta}$ & 0.196 & 0.207 \\
\hline$C_{l \beta}$ & -0.129 & -0.095 \\
\hline$C_{n \delta a}$ & 0.007 & 0.0027 \\
\hline$C_{n \delta r}$ & 0.137 & 0.0914 \\
\hline$C_{l \delta r}$ & -0.028 & -0.0052 \\
\hline
\end{tabular}

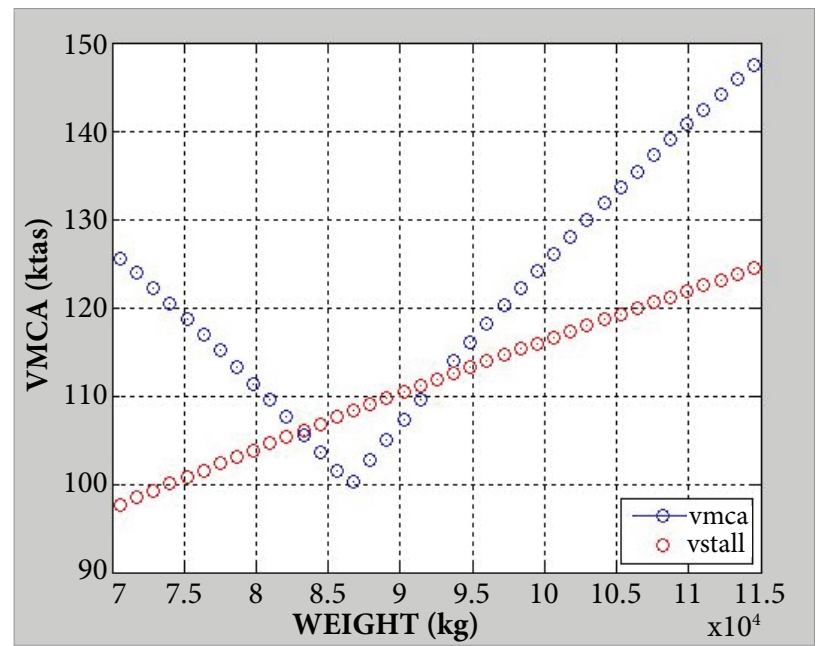

Figure 12. $V_{m c a}$ calculation by ITAIL (Boeing 757-200).

Table 6. Calculated tailplane areas for some airliners.

\begin{tabular}{|c|c|c|c|c|c|c|}
\hline \multirow{2}{*}{ Airplane } & \multicolumn{3}{|c|}{ HT area $\left(\mathrm{m}^{2}\right)$} & \multicolumn{3}{|c|}{ VT area $\left(\mathrm{m}^{2}\right]$} \\
\hline & Calculated & Actual & Deviation [\%] & Calculated & $\overline{\text { Actual }}$ & Deviation [\%] \\
\hline $\begin{array}{l}\text { Boeing 757-200 } \\
\text { (RB211-535E4) }\end{array}$ & 52.06 & 50.35 & +3.40 & 35.61 & 34.27 & +3.91 \\
\hline $\begin{array}{l}\text { Fokker } 100 \\
\text { (R\&R Tay 620) }\end{array}$ & 21.97 & 21.72 & +1.15 & 13.03 & 12.30 & +5.90 \\
\hline $\begin{array}{l}\text { Boeing 747-100 } \\
\text { (JT9D-7A) }\end{array}$ & 129.28 & 136.60 & -5.35 & 77.99 & 77.10 & +1.15 \\
\hline $\begin{array}{l}\text { Canadair CRJ-100ER } \\
\text { (GE CF34-A) }\end{array}$ & 9.67 & 9.44 & +2.44 & 9.73 & 9.18 & +5.99 \\
\hline $\begin{array}{l}\text { Boeing 737-100 } \\
\text { (JT8D-7) }\end{array}$ & 19.46 & 20.81 & -6.50 & 29.77 & 28.99 & +2.70 \\
\hline
\end{tabular}




\section{ENHANCED AERONAUTICAL AIRPLANE}

After ITAIL was validated against HT and VT areas found in a large variety of transport airplane areas, its methodology was incorporated into AA. From this point on, the ability of the enhanced AA to correctly calculate VT and HT areas was put under scrutiny. For this purpose, data of the Fokker 100 airliner were input in that application. Establishing a constraint to the static margin to be exactly $12.5 \%$ of MAC, the convergence process to determination of the HT area can be seen in Fig. 13. The parameter XLE in the abscissa axis is the distance from the airplane nose of the wing leadingedge point in the fuselage centerline. Figure 14 reveals the geometry variation and the wing repositioning until the convergence was achieved. AA also provides an artistic view of the final configuration, which was displayed in Fig. 14. The HT area that was calculated by AA was $22.1 \mathrm{~m}^{2}$, a deviation of $2.3 \%$ when compared to the Fokker 100 actual HT area, which is displayed in Table 5.

The VT area obtained with AA was then $13.6 \mathrm{~m}^{2}$, which obeys three criteria:

- the criterion that $V_{m c a}<1.2 V_{s}$ at MTOW, sea level takeoff resulted in an area of $6.2 \mathrm{~m}^{2}$;

- the controllability requirement demanded an area of $9.7 \mathrm{~m}^{2}$; and

- the static stability imposed the ultimate area of $13.6 \mathrm{~m}^{2}$ and drove the sizing.

A study about the impact of the variation of the quarterchord sweepback angle on the tailplane areas was carried out with AA using the Fokker 100 as baseline airplane. The results displayed in Fig. 15 indicated a decrease of the required HT area

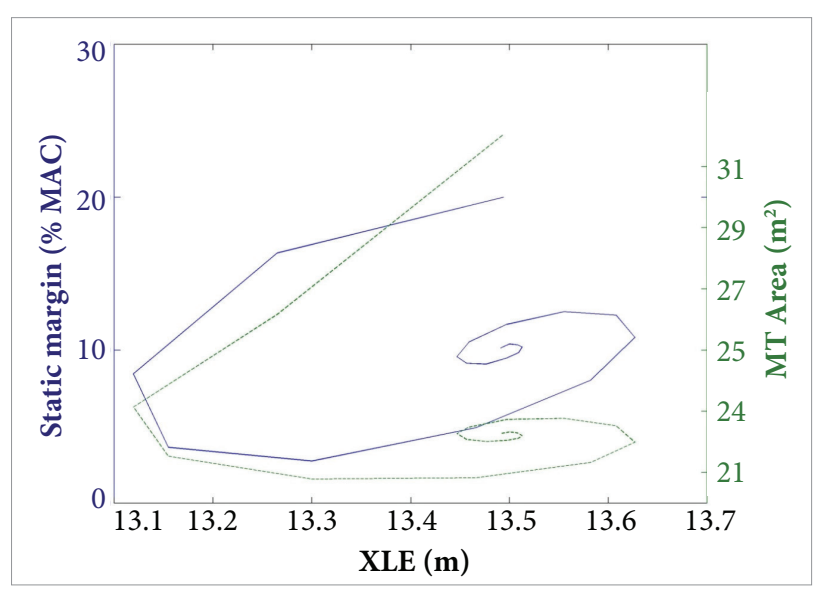

Figure 13. Static margin and horizontal tail area convergence process for the Fokker 100 airliner. of $22 \%$ if the sweepback angle varies from 17.5 to 33 degrees. No significant impact on VT area was recorded as expect. Sweptwing airplanes records improved directional stability because a restoring moment arises due to the differential drag forces acting on the port and starboard wings (Fig. 15 at bottom). For this reason, no significant change in VT area is expected as sweepback angle is increased taking into account that for aft-mounted engine configurations the stability criterion is critical. Figure 16 compares the calculated configurations for two configurations with distinct wing quarter-chord sweepback angles, 17.5 and 28 degrees. Static margin was fixed as $12.5 \%$ of MAC for both simulations and the vertical tail is the same for both configurations. The Fokker 100 is displayed in green

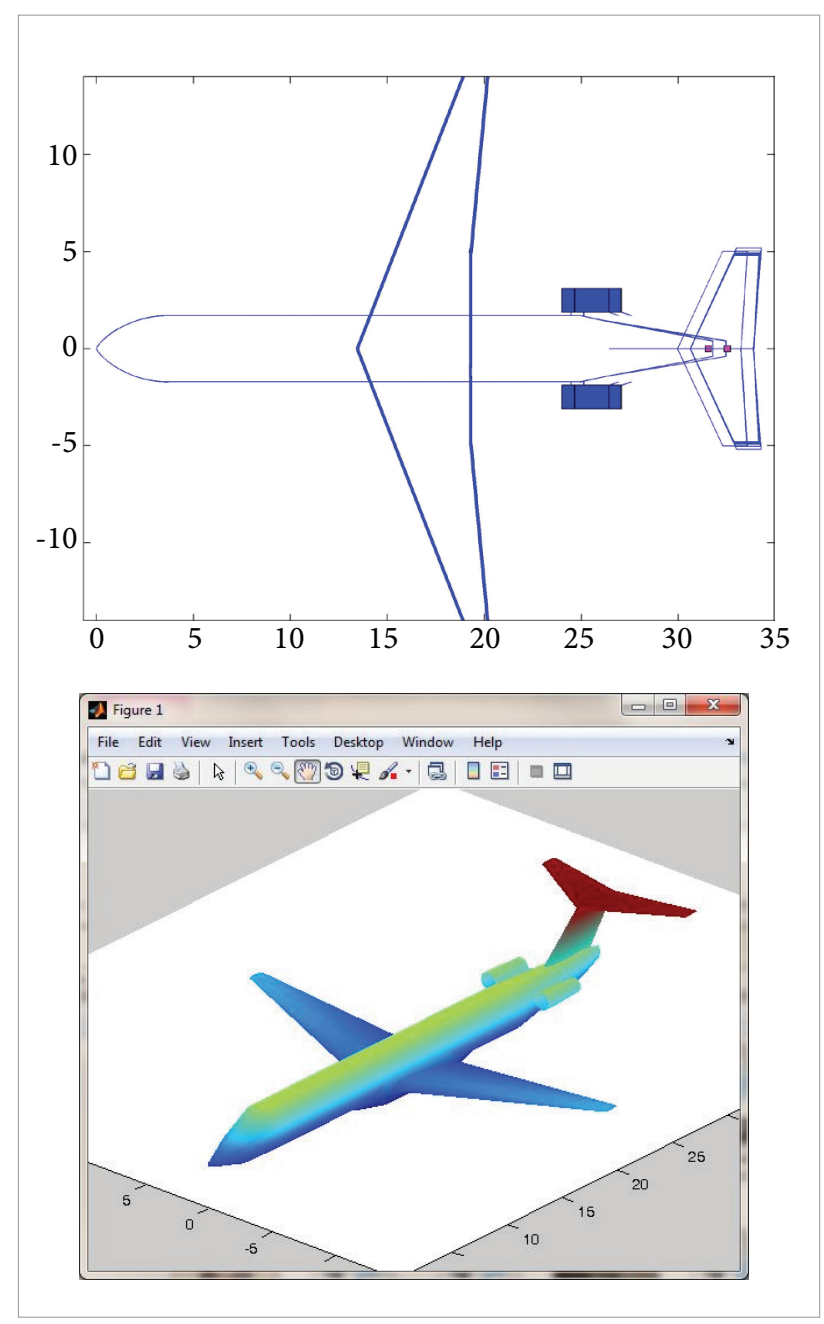

Figure 14. Above: variation of the configuration geometry during the convergence process for the horizontal and vertical tails sizing of the baseline configuration. Wing area and engine data are treated as input variables. Bottom: artistic view of the designed configuration. 


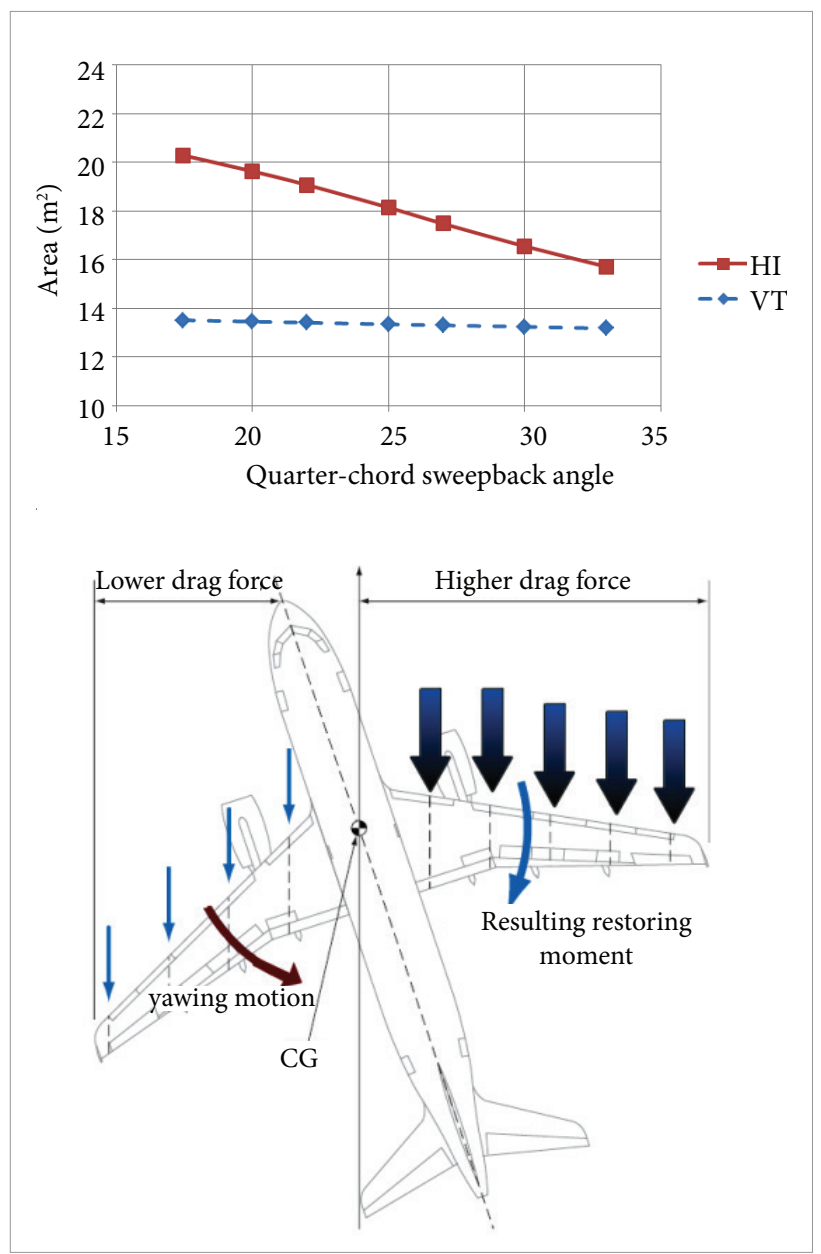

Figure 15. Above: tailplane area variation with wing quarter-chord sweepback angle of the Fokker 100 airplane. Values were obtained with AA calculator. Bottom: sweptwing airplanes produce a restoring moment improving the directional stability.

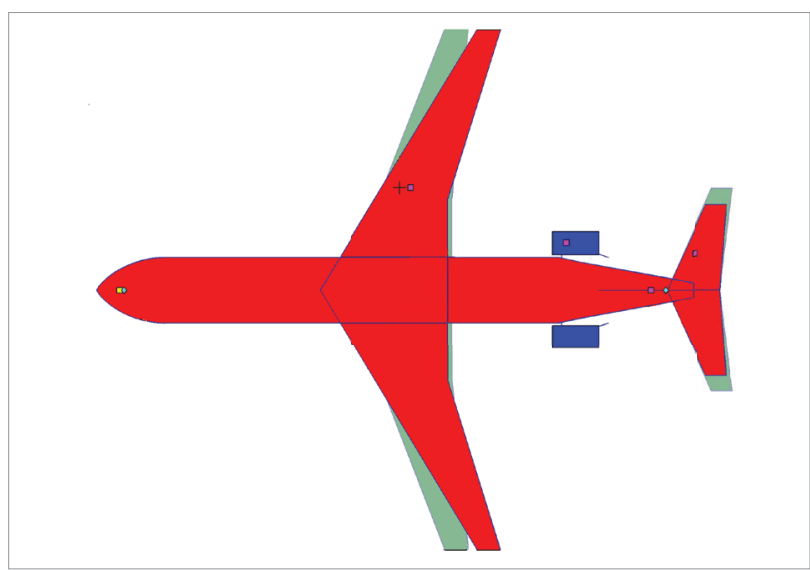

Figure 16. Comparison of the HT for the Fokker 100 (green color] and a derived confi guration with 28 degrees of wing sweepback angle. colors and features a larger horizontal tail than that of the configuration with higher sweepback angle. The CG location for the empty airplane and the wing aerodynamic center do not change significantly for both configurations. AA also provides an output graph of the short period frequency requirements for longitudinal flight quality in order to verify if the design complies with (Fig. 17).

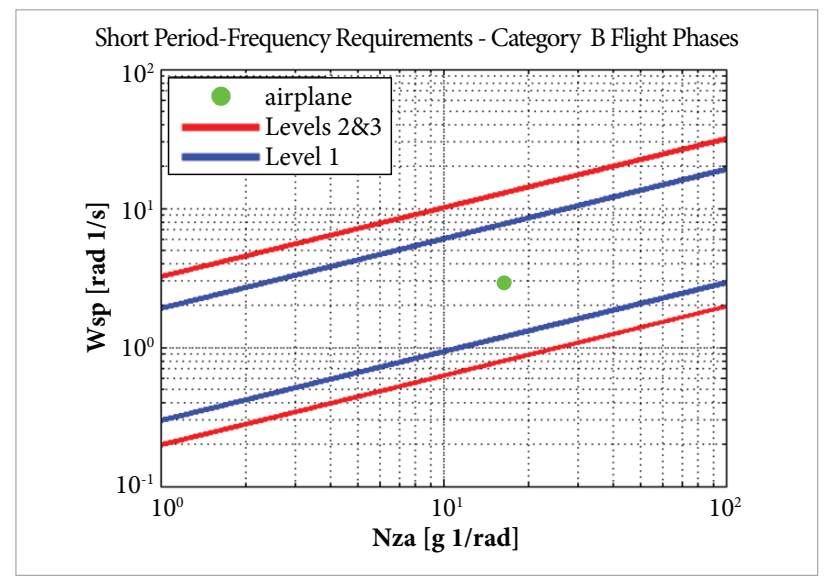

Figure 17. AA analysis for the Fokker 100, which is represented by the circle between the Level 1 boundaries.

\section{CONCLUDING REMARKS}

A MATLAB $^{\circledR}$ application called ITAIL was developed to validate a methodology for vertical and HT sizing of transport airplanes. ITAIL employs static stability and controllability criteria for tailplane design. The highest deviation found by the ITAIL application was that for the Boeing 737-100 HT area, i.e. 6.5\%. The agreement between calculated and actual figures for the areas can be considered excellent. A post-design check in order to guarantee that the dynamic stability behavior will be satisfactory is required. The results presented here corroborates that tailplanes areas of airliners can be usually determined by considering static stability and controllability requirements, with undesired dynamic behavior being fixed during flight test campaign if necessary.

The methodology embedded in ITAIL avoids a very arbitrary criterion to the sizing of transport airplanes tail surfaces, i.e. the tail volume coefficient. Thanks to the increase in computing power in the last ten years, conceptual airplane design has steadily become more sophisticated and has incorporated higherfidelity techniques to model airplane geometry and aeronautical disciplines. In this context, dropping very inaccurate methods like the tail volume coefficient fits well in this trend. 
An existing airplane calculator designated AA was enhanced with a higher fidelity approach for sizing horizontal and vertical tailplanes. AA is a MATLAB application tailored to be incorporated into MDO frameworks. Results obtained with AA using the methodology described in this work and incorporated by ITAIL revealed an excellent agreement with the VT and HT areas of the Fokker 100 airliner fitted with Rolls\&Royce Tay 620 engines.

$V_{\text {mca }}$ may become an important driver for the design of the VT if takeoff field length or climb requirements in second segment are very stringent. Both ITAIL and AA applications already consider $V_{m c a}$ for the VT sizing.

\section{REFERENCES}

Benson, T.J., 1995, "An Interactive Educational Tool for Turbojet Engines", Cleveland, Ohio, NASA Lewis Research Center.

Boeing Co., 2009, "Takeoff Performance", Boeing Electronic Training Material, Seattle.

Cavanaugh, M.A., 2004, "A MATLAB m-File to Calculate the Single Engine Minimum Control Speed in Air of a Jet Powered Aircraft", VMCmav1.m User's Manual, Virginia Tech, VA.

Centennial of Flight, "Dynamic Longitudinal, Directional, and Lateral Stability," Retrieved on November 12 2011, from http://www.centennialofflight. gov/essay/Theories_of_Flight/Stability_ll/TH27.htm

Chai, S.T. and Mason, W., 1996, "Aircraft Landing Gear Integration in Aircraft Conceptual Design”, MAD Report, MAD 96-09-01, Virginia, September.

Grasmeyer, J., 1998, "Stability and Control Derivative Estimation and Engine-Out Analysis," Virginia Tech Department of Aerospace and Ocean Engineering Report, VPI-AOE-254.

Grundlach IV, J.F., 1999, "Multidisciplinary Design Optimization and Industry Review of a 2010 Strut-Braced Wing Transonic Transport," Master of Aerospace Engineering Thesis, Virginia Polytechnic Institute and State University, Blacksburg, Virginia.

Heffley, R.K. and Jewell, W.F, 1972, "Aircraft Handling Qualities Data", NASA CR 2144.

Holst, T.L. and Thomas, S.D., 1982, "Numerical Solution of Transonic Wing Flow Fields", AIAA paper \# 82-105.

Jenkinson, L., Simpkin, P., Rhodes, D., 2001, "Civil Jet Aircraft Design", Retrieved on November 2 2011, from http://www.elsevierdirect.com/ companions/9780340741528/case-studies/default.htm

Karas, O.V. and Kovalev, V.E., 2011, "BLWF 28 User's Guide”, Moscow.
Loureiro, V., 2008, "Optimal design of Transport Airplane with a Realistic Engine Model in the Loop," Undergraduation Thesis, Instituto Tecnológico de Aeronáutica, São José dos Campos, Brazil.

Mattos, B.S. and Magalhães, P.E.C.S., 2012, "Conceptual Optimal Design of Airliners with Noise Constraints", 50 th Aerospace Sciences Meeting and Exhibit, Nashville, TN.

Raymer, D.P., 1999, “Aircraft Design: A Conceptual Approach”, $3^{\text {rd }}$ Ed, Washington D.C., AIAA.

Roskam, J., 1971, "Methods for Estimating Stability and Control Derivatives of Conventional Subsonic Airplanes," Roskam Aviation and Engineering Corporation, Lawrence, Kansas.

Roskam, J., 2000a, "Airplane Design, Part I: Preliminary Sizing of Airplanes," The University of Kansas, Lawrence, DARcorporation.

Roskam, J., 2000b, "Airplane Design, Part Vl: Preliminary Calculation of Aerodynamics, Thrust and Power Characteristics," The University of Kansas, Lawrence, DARcorporation.

Sadraey, M., 2009, "Aircraft Performance Analysis," Verlag Dr. Müller.

Scholz, D., 2011, "PreSTo - Aircraft Preliminary Sizing Tool - From Requirements to the Three-view Drawing", EWADE 2011 - 10 ${ }^{\text {th }}$ Workshop on Aircraft Design Education, Naples, Italy, May.

Toreenbeek, E., 1982, "Synthesis of Subsonic Airplane Design," Delft University Press, Delft, the Netherlands.

Videiro, P.L., 2012, "Wing Structural Optimization in Aircraft Conceptual Design," undergraduation thesis, Instituto Tecnológico de Aeronáutica, São José dos Campos, Brazil.

"World's Aircraft, "Fokker 100," 2013, Retrieved on June 3 2013, from http://www.aer.ita.br/ bmattos/mundo/airliner/fo100.htm

\section{LIST OF SYMBOLS}

$A R=$ Aspect ratio

$b=$ Span

$c_{\text {mac }}=$ Mean aerodynamic chord

$C=$ Lift coefficient

$C_{L}=$ Variantion of the lift coefficient with angle of attack

$C_{L \max }=$ Maximum lift coefficient of wing or airplane configuration

$\mathrm{Cm}_{e}=$ Moment coefficient due to engine

$\mathrm{Cm}_{0}=$ Moment coefficient

$\mathrm{Cm}_{\mathrm{O}_{\mathrm{w}}}=$ Moment coefficient of the wing - body combination

$d=$ diameter

$D=$ Drag force

$M_{\infty}=$ Freestream Mach number

MAC - Mean aerodynamic chord

$l=$ length

$L=$ Lift force

$q=$ Dynamic pressure

$S=$ Area

$T=$ Engine thrust

$V=$ Velocity

$W=$ weight $\alpha=$ Angle of attack

$\beta=$ Sideslip Angle

$\varepsilon=$ Downwash angle at horizontal tail

$\eta=$ Ratio between local and freestream dynamic pressure

$\phi=$ Bank angle

$\rho=$ Air density

$\Psi=$ Sweepback angle

SUBSCRIPTS

50 Half chord

ac Aerodynamic

CG Center of gravity

$e$ Engine

$h$ Horizontal tail

mca Minimum control speed in the air

mcg Minimum control speed in the ground

ref Reference (area, length, etc...)

$s$ Stall

$w$ Wing

$\infty$ Freestream 